\title{
Prediction of leaf number by linear regression models in cassava
}

\author{
M. S. A. Fakir, M. G. Mostafa, M. R. Karim and A. K. M. A. Prodhan \\ Department of Crop Botany, Bangladesh Agricultural University Mymensingh-2202, Bangladesh \\ E-mail: fakirmsa@yahoo.com
}

\begin{abstract}
Estimation of leaf number currently held on the plant and degree of leaf sheding occurred was carried out in two Cassava (Manihot esculenta) morphotypes (Philippine and Nagra) at Mymensingh $\left(24^{\circ} 75^{\prime} \mathrm{N} 90^{\circ} 50^{\prime} \mathrm{E}\right)$. Four linear regression Models were developed for estimating leaf number (LN) from length (L) of mainstem (MS) and primary branch $(P B)$ and they were $L^{M S}=-6.89+1.05 L^{M S}$ (Model \# 1) and $L^{M B}=-5.116+1.033 L^{P B}$ (Model \# ${ }^{P}$ ) for Philippine; and $\mathrm{LN}^{\mathrm{MS}}=-4.041+0.73 \mathrm{~L}^{\mathrm{MS}}$ (Model \# 3 ) and $\mathrm{LN}^{P B}=-1.597+0.707 \mathrm{~L}^{\mathrm{PB}}$ (Model \# 4) for Nagra morphotype. New leaf number produced in the mainstem $\left(\mathrm{LN}^{\mathrm{MS}}\right)$ and primary branch $\left(\mathrm{LN}^{\mathrm{PB}}\right)$, total leaf number in the mainstem ( $\left.T L^{\mathrm{MS}}\right)$ and primary branch $\left(T L^{P B}\right)$ of each morphotype were also counted for leaf abscission (LAB) prediction model and the results showed that the regression models of leaf abscission in the primary branch (LAB ${ }^{\mathrm{PB}}$ ) from new leaf in the primary branch $\left(L N^{P B}\right)$ was effective $\left(L A B^{P B}=-0.521+0.525 L N^{P B}\right)($ Model \# $\#)$. These regression Models showed linear relationships when actual leaf number was plotted against predicted leaf number and that this confirmed accuracy of the developed Models. Moreover, Models selection indices had high predictability (high $\mathrm{R}^{2}$ ) with minimum error (low error mean square error and percentage deviation). The selected Models appeared accurate and rapid, but can be used for estimation of leaf production in Philippine and Nagra morphotypes of Cassava.
\end{abstract}

Keywords: Manihot esculenta, Regression, Leaf production, Leaf abscission

\section{Introduction}

Cassava (Manihot esculenta Crantz) is a shrubby perennial and is valued for its underground starchy tuberous roots. Cassava roots are consumed as staple food in Africa and also used as raw material in garment, bakery, pharmaceutical, food and feed industry. The plant produces large simple, dark green, reddish veined leaves which are palmately divided into about 3 to 9 leaf-lobes, and 3 to 11 tubers per plant with each tuber being 30 to $40 \mathrm{~cm}$ long and 35 to $500 \mathrm{~g}$ weight (Cock et al., 1979 and Islam et al., 2007).

Leaf is the primary source of food production apparatus in Cassava. Leaf size and weight directly influence the growth and food storage in root (tubers) (Boerboom, 1978; Islam et al., 2008). Continuous leaf shed occurred accompanied by emergence of new leaf in Cassava. Therefore, the dynamics of leaf production in Cassava is a key factor for tuber yield enhancement. Hence leaf area, leaf number, leaf abscission are the key factor to Cassava yield improvement (Karim, 2004). There appears a relation between the number of leaves production on the branches and the number of prominent nodes (scars) on the branches. Even after sheding of the leaves, the number can be predicted by counting distinct scars marked by abscised leaves on the stem and branches. Therefore, the number of leaves produced in a certain length of the stem and branches can be predicted.

The measurement of leaf production of a plant is an important index of its growth and development and is commonly employed in Agronomical and Physiological studies. Literature on the prediction of leaf area from simple linear measurements of leaf-lobe length and width, leaf-lobe fresh and dry weights is reported in Cassava (Karim, et al 2010). There is no literature from previous study on prediction of leaf number and leaf abscission in Cassava. However, (Karim, 2004) conducted a study in Bangladesh on this aspect. The present research was conducted to develop and test regression models that would enable leaf number, and leaf abscission prediction from simple, linear, destructive and non-destructive measurements. 


\section{Materials and Methods}

Crop establishment: The experiment was conducted at the field laboratory of the Department of Crop Botany, Bangladesh Agricultural University, Mymensingh between May 2003 and November 2004. The soil was silt loam at a mean elevation of $18 \mathrm{~m}$ above the sea level belonging to the Sonatola soil series of non calcareous dark gray flood plain soil under the old Brahmaputra Flood Plain Agro-ecological zone-9 (FAO, 1988). The soil had total nitrogen $0.10 \%$, organic matter $1.35 \%$, available phosphorus $18.5 \mathrm{ppm}$, potassium $0.28 \mathrm{ppm}$, sulphur $18 \mathrm{ppm}, \mathrm{pH} 6.8$ (FAO, 1988). The cation exchange capacity (CEC) and fertility status of the soil were low and medium, respectively.

The experimental area was fertilized with cowdung $\left(16 \mathrm{t} \mathrm{ha}^{-1}\right)$, urea $\left(83 \mathrm{~kg} \mathrm{ha}^{-1)}\right.$, TSP $\left(62 \mathrm{~kg} \mathrm{ha}^{-1}\right)$, and MP $\left(62 \mathrm{~kg} \mathrm{ha}^{-1}\right)$ at time of final land preparation. The experiment consisted of two morphotypes viz., Philippine and Nagra. The cuttings from the stem of each morphotype were planted on $7^{\text {th }}$ May, 2003 in the unit plot of $4.5 \mathrm{~m}^{2}(3 \mathrm{~m} \times 1.5 \mathrm{~m})$. The experiment was replicated thrice. Healthy and uniform size (about $12 \mathrm{~cm}$ with 6 nodes) 12 months old stem cuttings, collected from the previous expt., were planted with an angle of $45^{\circ}$ from ground, placing two-third of the cutting in the soil. The distance between two stalks was $75 \mathrm{~cm}$ and 1 stem cutting was planted in each hole. The cuttings were treated with the fungicides Bavistin before planting ( $5 \mathrm{~g} / \mathrm{plot})$. Cutting was watered after planting and watering continued for several days until their establishment. Other cultural practices were carried out when needed (Karim, 2004).

Prediction of leaf number (LN) from shoot length (SL): A length of $30 \mathrm{~cm}$ both on the main stem (MS) and primary branch (PB) of each of the morphotypes, Philippine and Nagra, were used for estimation of node numbers in May, 2004 (Fig.1). At least 20-30 samples were studied. Node or leaf numbers in $30 \mathrm{~cm}$ length on MS and PB at the base, middle and top of the plant canopy were counted and then averaged. Correlation between MS length with MS leaf number, and that between length of PB and number of leaf in PB were estimated. Taking leaf number as dependent variable and main stem length as independent variable was formulated as $L N^{M S}=a+b L^{M S}$, where $L N=$ leaf number, $L$ is length of main stem (MS), $a$ is the constant and $b$ is the slop of the line. This equation was employed to estimate LN of another set of plants of each of the morphotypes. Further plotting of actual LN versus estimated LN was performed. Thus, prediction regression equation of $L N$ from plant height was tested. Similarly, the prediction of leaf number for the primary branches was also performed.

Estimating leaf abscission from total number of leaves (TL) and from number of new leaves (LN): Number of abscised leaf was estimated by counting the large scars left by the leaves on stem and branches (Fig.1). Number of TL, LN and abscised leaves in MS and PB at 10 days interval during 4 to 5 month from planting (storage root developmental stage) were counted. A total of 40-50 samples were used. A correlation between TL and number of leaves abscised (LAB) and that between $L N$ and $L A B$ in both MS and PB were estimated separately. Regression equations were $L A B=a+b L N$ and $L A B=a+b T L$ for predicting number of abscised leaves from $L N$ and $T L$, respectively were developed. These equations were employed to estimate number of leaves abscised from another sets of plants. Further, plotting of observed (values in the $x$-axis) versus predicted (values in the $y$-axis) number of leaves abscised showing linear relationship was performed. Thus prediction regression equations of number of leaves from $L N$ and TL were developed.

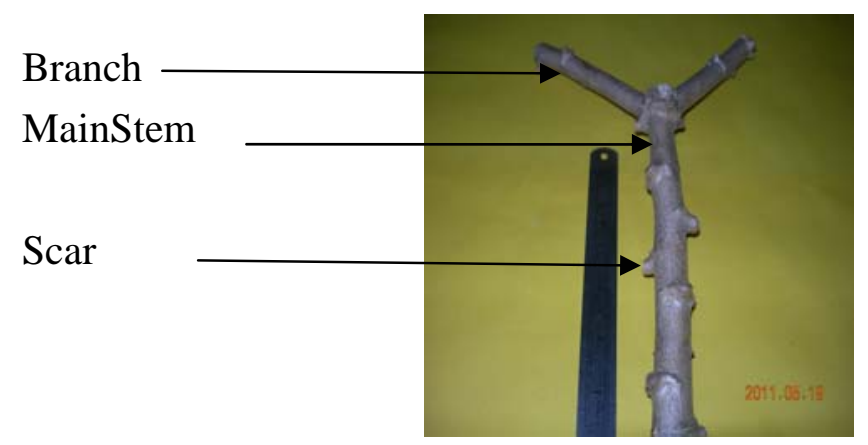

Fig.1. Mainstem and branches of Cassava showing prominent scar. Scars are the distinct marks left by leaves 
Statistical analysis: The data were compiled and analysed following the analysis of variance (ANOVA) technique and correlation study between the related data was also carried out with a computer package programme SPSS 10 for Windows. Regression analysis was also carried out.

\section{Results and Discussion}

Predicting number of leaf from shoot length in Philippine morphotype of Cassava: The correlation coefficient ( $r$ ) of length $\left(\mathrm{L}^{\mathrm{MS}}\right)$ with the leaf number $(\mathrm{LN})$ in the $\mathrm{MS}\left(\mathrm{LN}^{\mathrm{MS}}\right)$ and that between length of the primary branch $\left(\mathrm{L}^{\mathrm{PB}}\right)$ and leaf number of the primary branch $\left(\mathrm{LN}^{\mathrm{PB}}\right)$ are presented in the Table 1 . In Philippine morphotype, correlation coefficient of $L^{\mathrm{MS}}$ with $\mathrm{LN}^{\mathrm{MS}}$ was 0.945 and that with $\mathrm{LN}^{\mathrm{PB}}$ was 0.974 . Both the values of correlation coefficients were highly significant and the results suggest that potential for establishing prediction Model proposed. Coefficient of determination $\left(R^{2}\right)$ for Model \# 1 and 2 are presented in Table 2. In order to test and compare the regression Model a further 50 samples of the Philippine morphotypes of Cassava were recorded (Fig. 2).

Table 1. Correlation coefficient of length (L) with leaf number (LN) in the main stem (MS) and primary branch (PB) of two' Cassava morphotypes

\begin{tabular}{|c|l|l|l|l|}
\hline \multirow{2}{*}{$\begin{array}{l}\text { Independent } \\
\text { variables }\end{array}$} & \multicolumn{4}{|c|}{ Dependent variables } \\
\cline { 2 - 5 } & \multicolumn{2}{|c|}{$\mathrm{LN}^{\mathrm{MS}}$ Nagra } & \multicolumn{1}{c|}{ Philippine } & \multicolumn{1}{c|}{ Nagra } \\
\cline { 2 - 5 } & \multicolumn{1}{|c|}{ Philippine } & $0.895^{\star *}$ & - & - \\
\hline $\mathrm{L}^{\mathrm{MS}}$ & $0.945^{\star *}$ & - & $0.974^{* *}$ & $0.927^{* *}$ \\
\hline $\mathrm{L}^{\mathrm{MS}}$ & - & \multicolumn{2}{c}{} \\
\hline
\end{tabular}

Two asterisks denotes significant at $1 \%$ level of significance

The regression Model \# $1\left(R^{2}=0.893\right)$ and $2\left(R^{2}=0.948\right)$ showed high predictability (Table 2). The relationship between predicted leaf number and observed leaf number in the main stem and primary branch for 50 samples was plotted using Model \# I and 2 (Fig. 2. A-B). Most of the points were lying near the straight line, representing predicted leaf number $\approx$ observed leaf number. Model \# 1 and 2 , hence, were very simple, rapid and accurate for leaf number estimation from mainstem length.

Predicting number of leaf from shoot length in Nagra morphotype of Cassava: The value of ' $r$ ' between $L^{\mathrm{MS}}$ and $L N^{\mathrm{MS}}$ was 0.895 and correlation of $L^{\mathrm{PB}}$ with $\mathrm{LN}^{\mathrm{PB}}$ was 0.927 (Table 1). The ' $r$ ' value indicates that leaf number could be estimated from the Models. The value of $R^{2}$ for Models \# 3 and 4 are presented in Table 2. For testing and comparing the regression Models, 50 samples of Nagra morphotypes of Cassava were also selected for necessary measurement. The regression Models \# 3 $\left(R^{2}=0.801\right)$ and $4\left(R^{2}=0.859\right)$ showed higher predictability. Plots of actual leaf number calculated from the Model \# 3 and 4 with the good predictive ability showed linear relationship (Fig. 2C-D). Models \# 3 and 4 were simple, easy and rapid for leaf number estimation.

Table 2. Regression Models of predicting leaf number (LN) from length (L) of main stem (MS) and primary branch (PB) of two Cassava morphotypes

\begin{tabular}{|c|l|}
\hline Model Number & \multicolumn{1}{|c|}{ Regression Model } \\
\hline & \multicolumn{1}{|c|}{ Philippine } \\
\hline & Regression Model for estimating $\mathrm{LN}^{\mathrm{MS}}$ \\
\hline 1 & $\mathrm{LN}^{\mathrm{MS}}=-6.893+1.053 \mathrm{~L}^{\mathrm{MS}}, \mathrm{R}^{2}=0.893^{*}$ \\
\hline & Regression Model for estimating $\mathrm{LN}^{\mathrm{PB}}$ \\
\hline 2 & $\mathrm{LN}^{\mathrm{PB}}=-5.116+1.033 \mathrm{~L}^{\mathrm{PB}}, \mathrm{R}^{2}=0.948^{* *}$ \\
\hline & Nagra \\
\hline 3 & Regression Model for estimating $\mathrm{LN}^{\mathrm{MS}}$ \\
\hline & $\mathrm{LN} N^{\mathrm{MS}}=-4.041+0.734 \mathrm{~L}^{\mathrm{MS}}, \mathrm{R}^{2}=0.801^{*}$ \\
\hline 4 & Regression Model for estimating $\mathrm{LN}^{\mathrm{PB}}$ \\
\hline & $\mathrm{LN}^{\mathrm{PB}}=-1.597+0.707 \mathrm{~L}^{\mathrm{PB}}, \mathrm{R}^{2}=0.859^{*}$ \\
\hline
\end{tabular}

*,**: Significant at $P \leq 0.01$ and $P \leq 0.05$, respectively 
Relation of leaf abscission (LAB) with production of new leaf (LN): The significant and positive rvalues between the number of leaf abscission and production of new leaves in Cassava indicate that there appears a relationship between the variables (Table 3 ). There was a non-significant correlation between total number of leaves (TL) and LAB. Regression Models were developed for LAB counting LN as independent variables (Table 4). From the four Models only Model \# 2 had higher predictive ability $\left(R^{2}=0.667\right)$ (Table 4). This indicated that amount of leaf shed can fairly be predicted from counting of new leaves (characterized by light pink colour) only in primary branch in Philippine morphotype of Cassava. In the other Models possibly some other factors may have associated with leaf abscission, which were probably unaccounted, caused lower prediction ability as indicated by smaller $\mathrm{R}^{2}$ values.

Table 3. Correlation between leaf abscission (LAB) and new leaf number (LN) and total leaf number (TL) in main stem (MS) and primary branch (PB) of two Cassava morphotypes

\begin{tabular}{|c|l|l|l|l|}
\hline \multirow{2}{*}{$\begin{array}{c}\text { Independent } \\
\text { variables }\end{array}$} & \multicolumn{4}{|c|}{ Dependent variables } \\
\cline { 2 - 5 } & \multicolumn{1}{|c|}{$\mathrm{LAB}^{\mathrm{MS}}$ Nagra } & \multicolumn{2}{c|}{$\mathrm{LAB}^{\mathrm{PB}}$} \\
\hline & \multicolumn{1}{|c|}{ Philippine } & \multicolumn{1}{c|}{ Nagra } \\
\hline $\mathrm{LN}^{\mathrm{MS}}$ & $0.672^{* *}$ & $0.578^{* *}$ & - & - \\
\hline $\mathrm{TL}^{\mathrm{MS}}$ & $0.181 \mathrm{NS}$ & $0.054 \mathrm{NS}$ & - & - \\
\hline $\mathrm{LN}^{\mathrm{PB}}$ & - & - & $0.817^{* *}$ & $0.654^{* *}$ \\
\hline $\mathrm{TL}^{\mathrm{PB}}$ & - & - & $0.173 \mathrm{NS}$ & $0.183 \mathrm{NS}$ \\
\hline
\end{tabular}

Two asterisks denotes significant at $1 \%$ level of significance

Table 4. Regression Models for predicting leaf abscission (LAB) from new leaf (LN) in main stem (MS) and primary branch (PB) of two Cassava morphotypes

\begin{tabular}{|c|l|}
\hline Model Number & \multicolumn{1}{|c|}{ Regression Model } \\
\hline & \multicolumn{1}{|c|}{ Philippine } \\
\hline & Regression Model for estimating $\mathrm{LAB}^{\mathrm{MS}}$ \\
\hline 5 & $\mathrm{LAB}^{\mathrm{MS}}=-0.167+0.440 \mathrm{LN}^{\mathrm{MS}}, \mathrm{R}^{2}=0.451^{\mathrm{NS}}$ \\
\hline & Regression Model for estimating $\mathrm{LAB}^{\mathrm{PB}}$ \\
\hline & $\mathrm{LAB}^{\mathrm{PB}}=-0.521+0.525 \mathrm{LN}^{\mathrm{PB}}, \mathrm{R}^{2}=0.667^{*}$ \\
\hline & \multicolumn{1}{c|}{ Nagra } \\
\hline 7 & Regression Model for estimating $\mathrm{LAB}^{\mathrm{MS}}$ \\
\hline & $\mathrm{LAB}^{\mathrm{MS}}=-0.049+0.376 \mathrm{LN}^{\mathrm{MS}}, \mathrm{R}^{2}=0.334^{\mathrm{NS}}$ \\
\hline & ${\mathrm{Regression} \text { Model for estimating } \mathrm{LAB}^{\mathrm{PB}}}^{\mathrm{L}: \text { Significant at } \mathrm{P} \leq 0.05, \mathrm{NS}: \text { Not significant }}$ \\
\hline
\end{tabular}

Conventionally leaf production is measured/ estimated by counting leaves and it is always tedious. A study was considered to estimate number of leaves by counting prominent scars after leaf abscission in the Cassava stem. Scar number was significantly correlated with length (L) of main stem (MS) and primary branch (PB). In Philippine, correlation coefficient of $L^{\mathrm{MS}}$ with leaf number on $\mathrm{MS}\left(\mathrm{LN}^{\mathrm{MS}}\right)$ was 0.945 and that of $L^{\mathrm{PB}}$ with $L N^{\mathrm{MS}}$ was 0.974 (Table 1). The regression Model \# $1\left(R^{2}=0.893\right)$ and \# $2\left(R^{2}=0.948\right)$ showed high predictability (Table 2) in Philippine morphotype. In Nagra morphotype the correlation coefficient (r) of $L^{\mathrm{MS}}$ with $\mathrm{LN}^{\mathrm{MS}}$ was 0.895 and that of $\mathrm{L}^{\mathrm{PB}}$ with $\mathrm{LN}^{\mathrm{PB}}$ was 0.927 (Table 1). The regression Models \# $3\left(R^{2}=0.801\right)$ and \# $4\left(R^{2}=0.859\right)$ also showed high predictive potential for leaf number in Nagra morphotype. Therefore, leaf number can be estimated from stem/branch length (Tables 1, 2). The Models for estimating LN were further tested in plants from a separate samples. Co-linearity between observed and predicted values indicates its usefulness (Fig. 2). The Models, therefore, 1 and 2 in Philippine, 3 and 4 in Nagra can be used to predict counting of leaf number simply by measuring stem or branch length. 

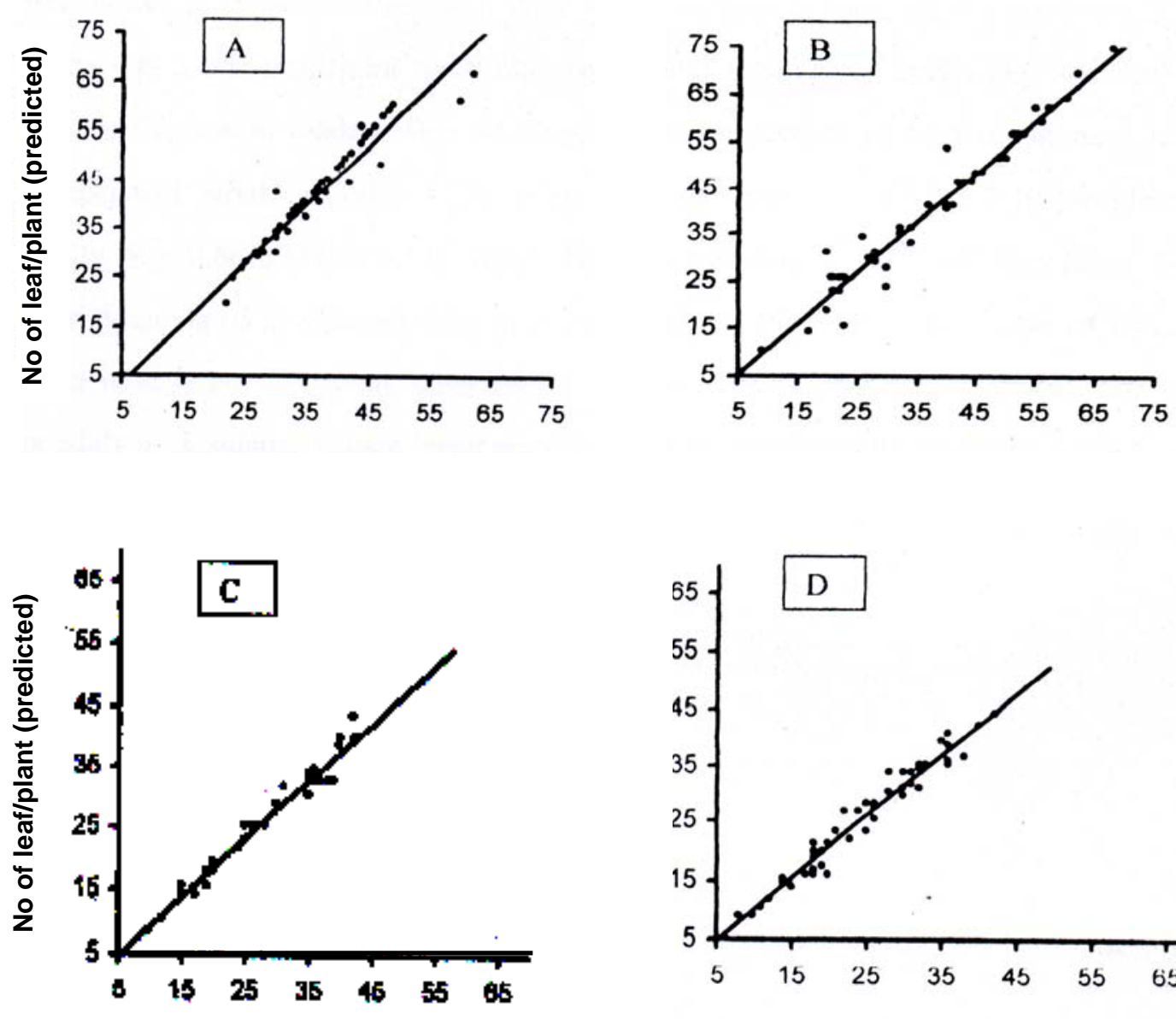

No. of leaf/plant (Actual)

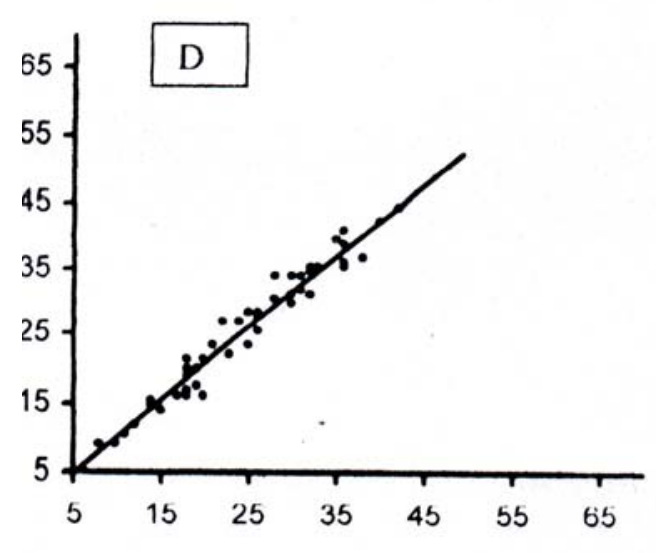

No. of leaf/plant (Actual)

Fig. 2. Comparison of leaf number estimated from four models with observed leaf number of 50 plants in Cassava (genotypes Philippine and Nagra) in which (A) the predicted leaf number $\left(\mathrm{LN}^{\mathrm{MS}}=-6.893+1.053 \mathrm{SL}^{\mathrm{MS}}, \mathrm{R}^{2}=0.893\right)$ was derived from model $\mathrm{I},(\mathrm{B})$ the predicted leaf number $\left(\mathrm{LN}^{\mathrm{PB}}=-5.116+1.033 \mathrm{SL}^{\mathrm{PB}}, \mathrm{R}^{2}=0.948\right)$ was derived from model 2 , (C) the predicted leaf number $\left(\mathrm{LN}^{\mathrm{MS}}=-4.041+0.734 \mathrm{SL} \mathrm{MS}^{\mathrm{MS}} \mathrm{R}^{2}=0.801\right.$ ) was derived from model 3 , (D) the predicted leaf number $\left(\mathrm{LN}^{\mathrm{PB}}=-1.597+0.707 \mathrm{SL}^{\mathrm{PB}}, \mathrm{R}^{2}=0.859\right)$ was derived from model 4

Study of degree of leaf abscission ( $L A B)$ is also tedious and time consuming. Marking, tagging and observing each leaf by frequent visiting the field is no doubt a cumbersome task. An attempt was taken to investigate the counting of leaf fall or leaf abscission by some other means such as by observing new leaves (LN) in a particular time course. There seemed to have a relationship between the number of leaves abscised and the number of new leaves emerged. The new leaves can easily be identified by their special catechu/pink colour. Other leaves are green of varied degree. Result showed a relationship between $L A B$ and $L N$ (Tables 3,4$)$. Of the four Models only Model \# 2 had higher predictability $\left(R^{2}=\right.$ 0.667 ) (Table 4). This indicated that degree of leaf-shed can fairly be predicted from counting new leaves only in primary branch $\left(\mathrm{LN}^{\mathrm{PB}}\right)$ in Philippine morphotype of Cassava. Karim (2004) also observed similar result. It was not possible to develop such Model and in the Nagra morphotype. There may be some other unaccounted factors which may have lowered ' $R$ ' value. Further works are needed to refine these Models for a particular morphotype and/or environment. 
For estimating leaf number, regression Model \# $1\left(R^{2}=0.893\right)$ and $2\left(R^{2}=0.948\right)$ in the PB of Nagra showed high predictability (Table 2). Relationship between actual leaf number and predicted leaf number in the MS and PB for 50 samples is presented (Fig. 2) where most of the points are lying near the straight-line indicating the fitness of the Model. Models \# 1 and 2 were easy and simple for leaf number estimation (Fig. 2A, B). Model \# $3\left(R^{2}=0.801\right)$ for the MS and Model \# $4\left(R^{2}=0.859\right)$ for the PB had high predictive ability in Nagra morphotype of Cassava (Table 2). Plots of actual leaf number versus predicted leaf number calculated from the Models \# 3 and 4 also showed linear relationship (Fig. 2C, D).

From the regression Models \# 1, 2, 3 and 4, only 2 had high predictive potential $\left(R^{2}=0.667\right)$ indicating leaf abscission can fairly be estimated from counting of new leaves in the primary branch of Philippine morphotype (Table 4).

The regression Models for number of leaf estimation (Models \# 1, 2, 3 and 4) and magnitude of leaf abscission (Model \# 2) had higher $\mathrm{R}^{2}$ and lower error mean square. These Models were accurate and rapid. Therefore, they can be used for estimation, leaf production and leaf abscission in Philippine and Nagra morphotypes of Cassava.

\section{References}

Boerboom, B.W.J. 1978. A Model of dry matter distribution in Cassava (Manihot esculenta Crantz). Netherlands J. Agric. Sci., 26: 267-277.

Cock, J.H., Franklin, D., Sadoval, G. and Juri, P. 1979. The ideal Cassava plants for maximum yield. Crop Sci., 19: $271-279$.

FAO. (Food and Agric. Organization) 1988. Land Resources Appraisal of Bangladesh for Agricultural Development. Rep.2. Agroecological Regions of Bangladesh. UNDP,FAO Rome, p. 116

Islam, A.T.M.T., Prodhan, A.K.M.A. and Fakir, M.S.A. 2007. Morphological differences in three Cassava morphotypes. J. Agrofor. Environ., 1(2): 115-118.

Islam, A., Islam, A.T.M.T., Mostafa, M.G. and Fakir, M.S.A. 2008. Effect of branch number on growth and yield in two cassava morphotypes. Bangladesh J. Agriculturist., 1(1): 1-6.

Karim, M.R. 2004. Estimation of leaf area and leaf production in two Cassava morphotypes. MS Thesis. Dept. Crop Botany, Bangladesh Agril. Univ. Mymensingh, Bangladesh.

Karim, M.R., Fakir, M.S.A., Mostafa, M.G., Prodhan, A.K.M.A.2010. Leaf Area Estimation by Linear regression models in Cassava (Morphotypes: Philippine) J. Agrofor. Environ., 4(1): 17-22. 